\title{
Impact of premix antimicrobial preparation and time to administration in septic patients
}

\author{
Wesley D. Kufel, PharmD, AAHIVP*; Robert W. Seabury, PharmD, BCPS*; Gregory M. Meola, \\ PharmD*; William Darko, BPharm, PharmD*; Luke A. Probst, PharmD, BCPS*; Christopher D. Miller, \\ PharmD, BCPS*
}

\section{ABSTRACT}

Objective: Strategies that reduce the time to antimicrobial administration, such as the availability of premix antimicrobials (PMAs) in the emergency department (ED), may better align with the goals of the Surviving Sepsis Campaign and improve outcomes in septic patients. The objective of this study was to evaluate the impact of antimicrobial preparation on time to administration in septic patients located in the emergency department (ED).

Methods: This was a retrospective, single-center, cohort study and adult patients with a diagnosis of sepsis who received at least one initial intravenous (IV) antimicrobial in the ED were included. Time to complete an empiric antimicrobial therapy was defined as the time between prescriber order entry and the infusion initiation time of the final antimicrobial agent of a patient's antimicrobial regimen. Appropriate, empiric antimicrobial therapy was based on treatment recommendations by nationally accepted guidelines for the specific indication.

Results: The first antimicrobial was initiated earlier when available as a PMA preparation (median (IQR): premix 25 minutes (16.5-42.3) vs. non-premix 46 minutes (20-102), $\mathrm{p}=0.027$ ). When comparing complete, empiric antimicrobial regimen administration, there was no difference in time to administration between regimens containing one or more non-premix antimicrobials and regimens containing all PMAs (median (IQR): premix 69 minutes (21-115) vs. non-premix 65 minutes (38.5-133.8); $p=0.455)$.

Conclusions: PMA preparations significantly reduced time to administration of the first antimicrobial agent for septic patients treated in the ED, but time to administration of subsequent antimicrobials were not improved.

\section{RÉSUMÉ}

Objectif: Les mesures visant à réduire le temps écoulé avant I'administration des antimicrobiens, telles que la disponibilité des préparations antimicrobiennes, prêtes à l'emploi (PAPE) au service des urgences (SU), peuvent faciliter la poursuite des objectifs de la Surviving Sepsis Campaign, et améliorer les résultats cliniques chez les patients septicémiques. L'étude visait à évaluer l'incidence des préparations antimicrobiennes sur le temps écoulé avant l'administration des médicaments chez les patients septicémiques traités au SU. Méthode: II s'agit d'une étude rétrospective de cohorte, unicentrique, menée chez des adultes chez qui un diagnostic de sepsie avait été posé et qui ont reçu au moins une première administration d'antimicrobiens par voie intraveineuse au SU. Le temps nécessaire pour terminer un traitement antimicrobien empirique a été défini comme le temps écoulé entre l'heure d'entrée de la prescription et I'heure du début de la perfusion du dernier agent antimicrobien, prévu dans le schéma posologique. Le traitement antimicrobien empirique approprié reposait sur des recommandations relatives à des traitements reconnus dans des lignes directrices acceptées à l'échelle nationale, dans une indication particulière.

Résultats: L'administration du premier antimicrobien commençait plus tôt lorsqu'une PAPE était disponible (temps médian [écart interquartile $\{E I Q\}]$ : PAPE : 25 minutes [16,542,3] contre préparations ordinaires : 46 minutes [20-102]; $p=0,027$ ). Par contre, en ce qui concerne l'administration complète des schémas antimicrobiens empiriques, il n'y avait pas de différence quant au temps écoulé avant l'administration des médicaments entre les schémas posologiques contenant un ou plusieurs antimicrobiens non prêts à l'emploi et les schémas posologiques contenant toutes des PAPE (temps médian [EIQ] : PAPE : 69 minutes [21-115] contre préparations ordinaires : 65 minutes $[38,5-133,8] ; p=0,455)$. Conclusions: Les PAPE ont sensiblement réduit le temps écoulé avant l'administration du premier agent antimicrobien chez les patients septicémiques traités au SU, mais n'ont eu aucune incidence sur celui avant l'administration des antimicrobiens suivants.

Keywords: premix, sepsis, administration time, antimicrobial, preparation, emergency department

From the *Department of Pharmacy, Upstate University Hospital, Syracuse, NY.

Correspondence to: Christopher D. Miller, Associate Director of Clinical Pharmacy Services and Research, Department of Pharmacy, Upstate University Hospital, 750 East Adams Street, Syracuse, NY 13210; Email: millechr@upstate.edu

(c) Canadian Association of Emergency Physicians C CJEM 2018;20(4):565-571

DOI 10.1017/cem.2017.33 


\section{INTRODUCTION}

Severe sepsis and septic shock in the emergency department (ED) represent a significant health care burden that is associated with high morbidity and mortality. ${ }^{1,2}$ In 2013, sepsis accounted for more than $\$ 23.7$ billion of total United States (US) hospital costs. ${ }^{3}$ It has been estimated that one patient arrives to the ED with this clinical presentation in the US every minute, with a mortality rate ranging from 25 to $50 \% .^{2,3}$ Antimicrobial therapy plays a major role in the treatment of severe sepsis and septic shock, yet there are several other factors that influence mortality outcomes, including fluid resuscitation and hemodynamic stability. ${ }^{4}$ In septic patients, appropriate selection of antimicrobial therapy based on suspected pathogens, source of infection, and patient-specific factors has been associated with reduced mortality. ${ }^{5}$

The Surviving Sepsis Campaign for the management of severe sepsis and septic shock recommends the administration of broad-spectrum antimicrobial therapy within 1 hour of septic shock recognition. ${ }^{6}$ These recommendations are largely based on moderate or low grades of supporting evidence. A retrospective study in the intensive care unit (ICU) showed that each 1 hour of delay in initiation of effective antimicrobial therapy after the onset of hypotension was associated with a $7.6 \%$ increase in mortality. ${ }^{7}$ Other studies have found inconsistent results concerning the association between prompt administration of antimicrobials in sepsis and mortality. ${ }^{8-23}$ Regardless of these inconsistent findings, initiation of antimicrobial therapy is generally considered a life-saving component in the resuscitation of a septic patient. ${ }^{24}$ Due to the complex issues and competing demands in the ED, administration of antimicrobials within the one-hour timeframe can be a challenging task to accomplish. ${ }^{25}$ Current guidelines recommend storing premix antimicrobials (PMAs) in the ED to avoid delays in administration if possible. ${ }^{6}$ It is theorized that PMAs in the ED would decrease the preparation time required by pharmacy or nursing staff to compound the intravenous (IV) antimicrobial agents and therefore provide earlier accessibility, although this recommendation appears to be solely based on expert opinion. ${ }^{6}$ There are inadequate data directly exploring the relationship between PMA use and administration time.

The primary objective of this study was to evaluate the impact of antimicrobial preparation on time to administration of the first as well as the complete empiric antimicrobial regimen in septic patients located in the ED. These data are required to better understand the potential value of PMAs on reducing time to antimicrobial administration and improving patient outcomes.

\section{METHODS}

This single-center, retrospective, cohort study was performed in the ED of a 472-bed academic medical center. The ED is a Level I trauma center and has an annual census of approximately 70,000 patients. Commonly used medications, including several antimicrobials, are stored in six automated dispensing cabinets (ADCs) in the ED. Additionally, the pharmacy department provides other medications not available in the ADCs 24 hours a day. This study was granted approval status by Upstate Medical University's institutional review board based on its retrospective/ observational design.

Adult ED patients with a diagnosis of sepsis were identified between June 1, 2015 and August 31, 2015 via a query of diagnosis codes in the electronic medical record. Adult patients with a primary diagnosis code of sepsis, severe sepsis, or septic shock with the initiation of antimicrobial therapy while in the ED were included in the study. Patients were reviewed consecutively and included if they received recommended empiric antimicrobial treatment. Recommended antimicrobial treatment was defined as any antimicrobial regimen recognized by nationally accepted guidelines for the empiric management of typical pathogens for the suspected source of infection and local hospital susceptibility patterns. ${ }^{26-32}$ If the suspected source of infection was unclear or unknown, piperacillin-tazobactam and vancomycin was defined as an acceptable initial empiric regimen. Patients were excluded if an antimicrobial was administered outside the ED location, such as the ICU, or if pertinent data were missing from the medical record.

A single reviewer, among multiple members of our research team, reviewed and extracted data from electronic medical records using a standardized data collection form. The reviewer collected demographic, clinical, and antimicrobial data. Periodic reviews of the data throughout the data collection process were performed by members of the research team to ensure proper and accurate data retrieval techniques. Patient demographic data included patient age, weight, and gender. Clinical data included admission serum creatinine (SCr), volume of IV fluids given in the ED, use of 
vasopressors in the ED, ICU admission, and length of hospital stay (LOHS). Antimicrobial data included drug name, time of antimicrobial order by physician and time of antimicrobial administration, antimicrobial storage site (ADC vs. pharmacy), and antimicrobial preparation (premix vs. non-premix). An antimicrobial agent was considered premixed if it was stored in an ED ADC in a preparation that did not require reconstitution and/or dilution prior to administration. An empiric regimen was considered premixed if all administered antimicrobials met the premixed definition. PMAs were used if the particular antimicrobial was commercially and readily available in the ADC located in the ED. Non-premix antimicrobials prepared by pharmacy personnel were used if the selected antimicrobial at the selected dose was not commercially available as a PMA.

All collected data were entered into a database created with IBM SPSS version 22.0. Descriptive statistics, including $\mathrm{n}(\%)$, mean \pm standard deviation $(\mathrm{SD})$, and median (interquartile range [IQR]) were used to summarize data. Student's t-test and the MannWhitney $U$ test were respectively used for comparisons of normally and non-normally distributed continuous data. The chi-square test for independence or Fisher's exact test was used for comparisons of categorical data. All tests were two-tailed, and a $\mathrm{p}$ value $<0.05$ was considered statistically significant. All statistical analyses were performed using IBM SPSS 22.0.

\section{RESULTS}

Ninety-seven patients were included in the final analysis. Fifty-two percent $(50 / 97 ; 52 \%)$ were female, and the average age (year) and weight $(\mathrm{kg}) \pm \mathrm{SD}$ were $56 \pm$ 19 years and $77 \pm 25 \mathrm{~kg}$, respectively. Mean SCr $(\mu \mathrm{mol} / \mathrm{L}) \pm \mathrm{SD}$ was $1.4 \pm 1.4$, and on average $964 \mathrm{~mL} \pm$ $706 \mathrm{~mL}$ of IV fluid was administered in the ED. Eighteen of 97 patients (19\%) required vasopressors, and 32\% (31/97) required an ICU admission. Mean LOHS (days) \pm SD was $9.2 \pm 10.4$ days. Common infection sources included skin and soft tissue $(25 / 97 ; 26 \%)$, urinary infection (19/97; 20\%), health care-associated lung infection (18/97; $19 \%$ ), and community-acquired lung infection (17/97; $18 \%)$. There were no statistically significant demographic or clinical differences between comparison groups.

Table 1 describes the antimicrobials used in 97 empirical regimens. In total, 165 antimicrobials were administered. Among the most commonly utilized were vancomycin $(41 / 165 ; 25 \%)$, third- or fourth-generation cephalosporins $(39 / 165 ; 24 \%)$, and piperacillintazobactam $(38 / 165 ; 23 \%)$. Most patients received more than one antimicrobial $(59 / 97 ; 61 \%)$, while $6.2 \%(6 / 97)$ received more than two antimicrobials. Premix antimicrobials were used $55 \%$ of the time (91/165), and $62 \%(60 / 97)$ of the empirical regimens contained at least one or more non-premixed antimicrobial. Premixed antimicrobials were commonly the first- $(58 / 97$; $50 \%)$ and second-administered antimicrobials (31/59; $53 \%)$. Non-premixed antimicrobials were more commonly administered third (4/6; 67\%). The first antimicrobial was administered within 1 and 3 hours of physician order entry for 75\% (73/97) and 97\% (94/97) of patients, respectively. The final antimicrobial of the patient's empirical regimen was administered within 1 and 3 hours of physician order entry in 49\% (47/97) and $84 \%(81 / 97)$ of patients, respectively.

Figure 1 describes the impact of preparation on the time from order entry until first antimicrobial administration. The first antimicrobial was initiated sooner when available as a PMA preparation (median (IQR): premix 25 minutes (16.5-42.3) vs. non-premix 46 minutes (20-102, $\mathrm{p}=0.027)$. However, the proportion of patients with the first antimicrobial initiated within 1 (premix $79.3 \%$ vs. non-premix $69.2 \%, p=0.338$ ) and 3 hours

\begin{tabular}{lc|}
\hline Table 1. Antimicrobials administered in the ED \\
\hline 1st antimicrobial, $\mathrm{n}(\%)$ & $35(36.1)$ \\
3rd or 4th generation cephalosporin & $30(30.9)$ \\
Piperacillin-tazobactam & $9(9.3)$ \\
Vancomycin & $9(9.3)$ \\
Fluoroquinolone & $5(5.2)$ \\
1st generation cephalosporin & $2(2.1)$ \\
Ampicillin or ampicillin-sulbactam & $1(1.0)$ \\
Macrolide & $6(6.2)$ \\
Other & \\
2nd antimicrobial, n (\%) & $34(35.0)$ \\
None & $29(29.9)$ \\
Vancomycin & $7(7.2)$ \\
Piperacillin-tazobactam & $14(14.4)$ \\
Macrolide & $5(5.2)$ \\
3rd or 4th generation cephalosporin & $1(1.0)$ \\
1st generation cephalosporin & $1(1.0)$ \\
Acyclovir & $6(6.2)$ \\
Other & \\
3rd antimicrobial, n (\%) & $91(93.8)$ \\
None & $3(3.1)$ \\
Vancomycin & $2(2.1)$ \\
Acyclovir & $1(1.0)$ \\
Piperacillin-tazobactam &
\end{tabular}




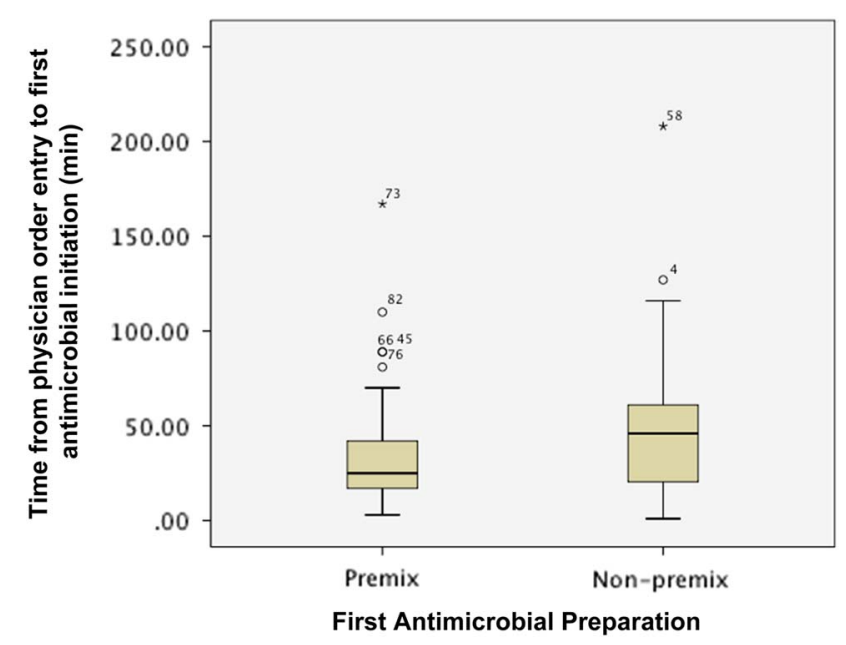

Figure 1. Impact of preparation on time from physician order entry to administration of first antimicrobial agent. * indicates the extreme value.

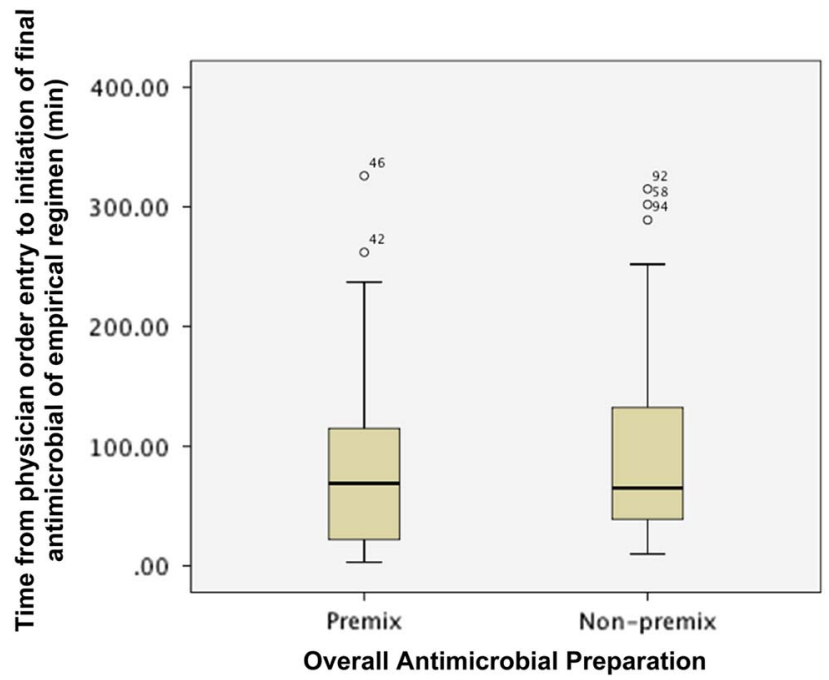

Figure 2. Impact of preparation on time from physician order entry to administration of final antimicrobial of an empirical regimen.

(premix $98.3 \%$ vs. non-premix 94.9\%, $\mathrm{p}=0.563$ ) of physician order entry was similar between groups.

Figure 2 describes the impact of preparation on the time from order entry until administration of the final antimicrobial agent of an empirical regimen. The final antimicrobial agent was administered at a similar time for empirical regimens containing at least one or more antimicrobial agents, regardless of whether the drug was available as a premix or non-premix preparation (median (IQR): premix $69 \min (21-115)$ vs. non-premix 65 min (38.5-133.8); $\mathrm{p}=0.455)$. The proportion of patients with their final antimicrobial agent administered within 1 (premix $48.6 \%$ vs. non-premix $48.3 \%$, $\mathrm{p}=1.000$ ) and 3 hours (premix $86.5 \%$ vs. non-premix $81.6 \%, \mathrm{p}=0.587$ ) of physician order entry was similar between groups.

\section{DISCUSSION}

The Surviving Sepsis Campaign guidelines recommend administration of effective antimicrobials within the first hour of recognition of severe sepsis (grade 1C) and septic shock (grade 1B). ${ }^{6}$ This recommendation is mostly based on a retrospective study that showed that each 1-hour delay in the administration of effective antimicrobial therapy was associated with a 7.6\% increase in mortality in septic shock. ${ }^{7}$ An antimicrobial was considered effective if it had in-vitro activity against the causative pathogen. More recent information also suggests that delays in antimicrobial administration also increases mortality in sepsis and severe sepsis. Liu and colleagues ${ }^{33}$ performed a retrospective study in a cohort of more than 35,000 patients with sepsis, severe sepsis, and septic shock. Each hour delay in antibiotic administration was associated with an $11 \%$ increased risk for in-hospital mortality risk with severe sepsis (OR 1.08; 95\% CI 1.02-1.14; $\mathrm{p}=0.01)$. Sisk and colleagues ${ }^{34}$ performed a retrospective case-control study of ED patients with sepsis and noted that early antibiotic administration was associated with lower 28-day mortality ( 17.1 vs. $22.8 \%, \mathrm{p}=0.01)$.

The delivery of effective antimicrobials in sepsis, severe sepsis, and septic shock is complicated by the uncertainty of the causative organism at the time of recognition. In these situations, clinicians must select antimicrobials with activity against common organisms and organisms with high mortality risk. ${ }^{6}$ Ani and colleagues performed a retrospective analysis of more than 5,000,000 cases of severe sepsis. ${ }^{35}$ Gram-negative bacteria were the most common causative organism (51.5\% of cases), and resistant gram-negative organisms such as Pseudomonas species (17.6\% of gram-negative cases) were frequently observed. Gram-positive infections were not uncommon, representing $45.6 \%$ of cases, and methicillin-resistant Staphylococcus aureus (MRSA) was associated with an increased mortality risk (HR 1.38, 95\% CI 1.33-1.44). Unfortunately, no single antimicrobial has activity against all of these organisms, and multiple antimicrobials are frequently required to provide the highest chance for effective treatment. The administration of multiple antimicrobials can be logistically difficult, and administration delays can occur. To enhance the likelihood that 
antimicrobials are infused promptly, the Surviving Sepsis Campaign guidelines recommend using PMA preparations. ${ }^{6}$ This recommendation is logical, as non-PMA preparations require nursing or pharmacy staff to compound the antimicrobial agent, which has the potential to cause treatment delays. However, the impact of PMA preparations on administration times in sepsis has not been previously assessed.

To the best of our knowledge, our study is the first to address PMA preparation as an independent factor in antimicrobial administration time for septic patients in the ED. PMA preparations were associated with a significant reduction in time to administration for the first antimicrobial agent. Though the proportion receiving their first antibiotic within an hour was not statistically greater with PMA preparations, this was likely a function of sample size, as the absolute difference between groups was approximately $10 \%$. The clinical significance of this observation is uncertain. Considering the variance in bacterial aetiology in sepsis, severe sepsis, and septic shock, time to administration of appropriate empirical antimicrobials is likely a better assessment of initial management, and many patients will require prompt administration of several antibiotics to achieve empirically appropriate treatment. PMAs were not associated with more rapid administration of appropriate empirical treatment (median (IQR): premix 69 minutes (21-115) vs. non-premix 65 minutes $(38.5-133.8) ; \mathrm{p}=0.455)$ or more frequent administration of appropriate empirical treatment within 1 (premix $48.6 \%$ vs. non-premix $48.3 \%, \mathrm{p}=1.000$ ) and 3 hours (premix $86.5 \%$ vs. nonpremix $81.6 \%, \mathrm{p}=0.587$ ) of physician order entry.

Like many others, our institution uses vancomycin and piperacillin-tazobactam as the primary antimicrobial agents for the empiric treatment of sepsis, severe sepsis, and septic shock, especially when the source is unknown initially. Both of these antimicrobials are available as premix preparations and are stored in all ADCs, including in the ED. These PMAs have some limitations that potentially constrain their utility in the management of sepsis, severe sepsis, and septic shock at our institution, most notably that there are conflicting reports concerning y-site compatibility as well as recent changes in our local piperacillin-tazobactam susceptibility patterns. We recognize these limitations but elected not to change our current practice because we do not carry a premix alternative for piperacillintazobactam. While there may be other contributions to administration delays of antimicrobial agents, our study primarily focuses on the impact of PMAs as one aspect of antimicrobial administration in this critically ill patient population.

\section{LIMITATIONS}

Our study has several important limitations to consider. First, it was performed at a single-center ED and may therefore not be generalizable to other institutions or settings. Other institutions may not have access to PMA preparations in their ADCs for ease of administration and may have different ED protocols. Second, our retrospective observational study design and relatively small sample size without an a-priori power analysis limited our ability to determine a causal relationship between PMA preparation administration time and clinical outcomes such as mortality. Lastly, we primarily focused on one practical element, antimicrobial preparation, that may impact antimicrobial administration time. We did not specifically characterize each patient's severity of illness using a severity-of-illness scale. However, the frequency of vasopressor use and ICU admission were similar whether PMAs or non-PMAs were given, potentially indicating a similar illness severity. Finally, there may be several other factors that may delay antimicrobial administration in septic patients that were not accounted for in our study.

\section{CONCLUSIONS}

Our study aimed to address whether PMA preparations decreased administration time in septic patients. We found that PMA preparations significantly reduced time to administration of the first antimicrobial agent for septic patients treated in the ED, but time to administration of subsequent antimicrobials was not improved. Strategies, including the availability of PMAs in ADCs in the ED, coupled with other schematics, may further reduce the time to antimicrobial administration in septic patients in the ED. Further research over a longer period of time in various settings is needed to quantify the impact of PMA preparations on antimicrobial administration time and clinical outcomes such as mortality.

Acknowledgements. To the pharmacy staff and Emergency Department at Upstate University Hospital for their gracious assistance and support in the operations of this project. 


\section{SUPPLEMENTARY MATERIALS}

To view supplementary material for this article, please visit https://doi.org/10.1017/cem.2017.33

\section{REFERENCES}

1. Cohen J, Vincent JL, Adhikari NK, et al. Sepsis: a roadmap for future research. Lancet Infect Dis 2005;15:581-614.

2. Wang HE, Shapiro NI, Angus DC, Yealy DM. National estimates of severe sepsis in United States emergency departments. Crit Care Med 2007;35(8):1928-36.

3. Torio CM, Moore BJ. National Inpatient Hospital Costs: The Most Expensive Conditions by Payer, 2013. HCUP statistical brief no. 204. Rockville, MD: Agency for Healthcare Research and Quality; 2016. Available at: http://www.hcup-us.ahrq.gov/reports/statbriefs/sb204-MostExpensive-Hospital-Conditions.pdf (accessed May 9, 2017).

4. Rivers E, Nguyen B, Havstad S, et al. Early goal-directed therapy in the treatment of severe sepsis and septic shock. N Engl 7 Med 2001;345(19):1368-77.

5. Barie PS, Hydo LJ, Shou J, Larone DH, Eachempati SR. Influence of antibiotic therapy on mortality of critical surgical illness caused or complicated by infection. Surg Infect (Larchmt) 2005;6(1):41-54.

6. Dellinger RP, Levy MM, Rhodes A, et al. Surviving Sepsis Campaign: international guidelines for management of severe sepsis and septic shock, 2012. Intensive Care Med 2013;39(2):165-228.

7. Kumar A, Roberts D, Wood KE, et al. Duration of hypotension before initiation of effective antimicrobial therapy is the critical determinant of survival in human septic shock. Crit Care Med 2006;34(6):1589-96.

8. Puskarich MA, Trzeciak S, Shapiro NI, et al. Association between timing of antibiotic administration and mortality from septic shock in patients treated with a quantitative resuscitation protocol. Crit Care Med 2011; 39(9):2066-71.

9. Sterling SA, Miller WR, Pryor J, Puskarich MA, Jones AE. The impact of timing of antimicrobials on outcomes in severe sepsis and septic shock: a systematic review and meta-analysis. Crit Care Med 2015;43(9):1907-15.

10. Labelle A, Juang P, Reichley R, et al. The determinants of hospital mortality among patients with septic shock receiving appropriate initial antibiotic treatment. Crit Care Med 2012;40(7):2016-21.

11. Siddiqui S, Razzak J. Early versus late pre-intensive care unit admission broad spectrum antibiotics for severe sepsis in adults. Cocbrane Database Syst Rev 2010;(10):CD007081.

12. Ryoo SM, Kim WY, Sohn CH, et al. Prognostic value of timing of antibiotic administration in patients with septic shock treated with early quantitative resuscitation. Am f Med Sci 2015;349(4):328-33.

13. Levy MM, Dellinger RP, Townsend SR, et al. The Surviving Sepsis Campaign: results of an international guideline-based performance improvement program targeting severe sepsis. Crit Care Med 2010;38(2):367-74.
14. Morrell M, Fraser VJ, Kollef MH. Delaying the empiric treatment of candida bloodstream infection until positive blood culture results are obtained: a potential risk factor for hospital mortality. Antimicrob Agents Chemother 2005; 49(9):3640-5.

15. Ferrer R, Artigas A, Suarez D, et al. Effectiveness of treatments for severe sepsis: a prospective, multicenter, observational study. Am 7 Respir Crit Care Med 2009; 180(9):861-6.

16. Castellanos-Ortega A, Suberviola B, García-Astudillo LA, et al. Impact of the Surviving Sepsis Campaign protocols on hospital length of stay and mortality in septic shock patients: results of a three-year follow-up quasi-experimental study. Crit Care Med 2010;38(4):1036-43.

17. El Solh AA, Akinnusi ME, Alsawalha LN, Pineda LA. Outcome of septic shock in older adults after implementation of the sepsis "bundle.". 7 Am Geriatr Soc 2008; 56(2):272-8.

18. Gurnani PK, Patel GP, Crank CW, et al. Impact of the implementation of a sepsis protocol for the management of fluid-refractory septic shock: a single-center, before-andafter study. Clin Ther 2010;32(7):1285-93.

19. Larsen GY, Mecham N, Greenberg R. An emergency department septic shock protocol and care guideline for children initiated at triage. Pediatrics 2011;127(6):e1585-92.

20. Barochia AV, Cui X, Vitberg D, et al. Bundled care for septic shock: an analysis of clinical trials. Crit Care Med 2010;38(2):668-78.

21. Ferrer R, Martin-Loeches I, Phillips G, et al. Empiric antibiotic treatment reduces mortality in severe sepsis and septic shock from the first hour: results from a guidelinebased performance improvement program. Crit Care Med 2014;42(8):1749-55.

22. Burnham JP, Lane MA, Kollef MH. Impact of sepsis classification and multidrug-resistance status on outcome among patients treated with appropriate therapy. Crit Care Med 2015;43:1580-6.

23. Burnham JP, Kollef MH. Timing of appropriate antibiotics in sepsis: how much does each hour matter? Crit Care Med 2016;44(2):e109-10.

24. Gaieski DF, Mikkelsen ME, Band RA, et al. Impact of time to antibiotics on survival in patients with severe sepsis or septic shock in whom early goal-directed therapy was initiated in the emergency department. Crit Care Med 2010; 38(4):1045-53.

25. Kanji Z, Dumaresque C. Time to effective antibiotic administration in adult patients with septic shock: a descriptive analysis. Intensive Crit Care Nurs 2012;28(5):288-93.

26. Tunkel AR, Hartman BJ, Kaplan SL, et al. Practice guidelines for the management of bacterial meningitis. Clin Infect Dis 2004;39(9):1267-84.

27. Stevens DL, Bisno AL, Chambers HF, et al. Practice guidelines for the diagnosis and management of skin and soft tissue infections: 2014 update by the Infectious Diseases Society of America. Clin Infect Dis 2014;59(2):e10-52.

28. Mandell LA, Wunderink RG, Anzueto A, et al. Infectious Diseases Society of America/American Thoracic Society consensus guidelines on the management of communityacquired pneumonia in adults. Clin Infect Dis 2007; 44(2 Suppl):S27-72. 
29. Guidelines for the management of adults with hospital-acquired. ventilator-associated, and healthcareassociated pneumonia. Am 7 Respir Crit Care Med 2005; 171(4):388-416.

30. Gupta K, Hooton TM, Naber KG, et al. International clinical practice guidelines for the treatment of acute uncomplicated cystitis and pyelonephritis in women: a 2010 update by the Infectious Diseases Society of America and the European Society for Microbiology and Infectious Diseases. Clin Infect Dis 2011;52(5):e103-20.

31. Hooton TM, Bradley SF, Cardenas DD, et al. Diagnosis, prevention, and treatment of catheter-associated urinary tract infection in adults: 2009 International Clinical Practice Guidelines from the Infectious Diseases Society of America. Clin Infect Dis 2010;50(5):625-63.
32. Solomkin JS, Mazuski JE, Bradley JS, et al. Diagnosis and management of complicated intra-abdominal infection in adults and children: guidelines by the Surgical Infection Society and the Infectious Diseases Society of America. Clin Infect Dis 2010;50(2):133-64.

33. Liu VX, Fielding-Singh V, Greene JD, et al. The Timing of Early Antibiotics and Hospital Mortality in Sepsis. Am 7 Respir Crit Care Med 2017; doi:10.1164/rccm.201609-1848OC.

34. Sisk M, Kashiouris MG, Pedram S, et al. Antibiotic delivery delays and mortality among patients with sepsis: a propensitymatched case-control study. Am 7 Respir Crit Care Med 2016;193:A2740.

35. Ani C, Farshidpanah S, Bellinghausen stewart A, Nguyen HB. Variations in organism-specific severe sepsis mortality in the United States: 1999-2008. Crit Care Med 2015;43(1):65-77. 